\title{
Smoke-free legislation has potential to reduce the harmful effects of tobacco smoke exposure
}

\author{
From the author:
}

T. Faber and colleagues correctly note that the implementation of smoke-free legislation has great potential to reduce the harmful effects of tobacco smoke exposure in children. A smoke-free environment represents $\mathrm{P}$ in the MPOWER programme developed by the World Health Organization (WHO) framework convention on tobacco control which aims to control the tobacco epidemic [1]. The acronym MPOWER stands for M: monitor tobacco use and prevention policies; P: protect people from tobacco smoke; O: offer help to quit tobacco smoking; W: warn about the dangers of tobacco; E: enforce bans on tobacco advertising, promotion and sponsorship; and R: raise taxes on tobacco [1]. Data from the WHO shows that in 2015 only 49 countries, with nearly $20 \%$ of the world's population, implemented completely policies for a smoke-free environment, thus showing that it is not easy to establish legislative smoking bans in national or even regional settings. Moreover, evidence regarding the effectiveness of legislative smoking bans in public places for reducing harm from second-hand smoke (SHS) exposure is inconclusive. That fact that studies are limited to the nonrandomised controlled trials available in some countries [2] means that more robust evidence is warranted to evaluate the impact of legislation prohibiting smoking in public places, particularly in developing countries. However, it does not mean that it is impossible to conduct such studies-it is possible as long the countries in question have the intention to change! On a different note, raising taxes on cigarettes and other tobacco products shows a reduction in the number of smokers in some countries, including China and France, although more evidence is needed [1]. Lastly, regardless of which programme is most successful in reducing the harmful effects of tobacco, people should realise that protecting pregnant women and children from the harmful effects of SHS exposure is crucial!

0

@ERSpublications

Smoke-free legislation has potential to reduce the harmful effects of tobacco smoke exposure http://ow.ly/PumW305Jv1d

Elida Zairina

Dept of Pharmacy Practice, Faculty of Pharmacy, Universitas Airlangga, Surabaya, Indonesia.

Correspondence: Elida Zairina, Dept of Pharmacy Practice, Faculty of Pharmacy, Universitas Airlangga, Jl. Darmawangsa Dalam, Surabaya, 60286, Indonesia. E-mail: elida-z@ff.unair.ac.id

Received: Oct 242016 | Accepted: Oct 242016

Conflict of interest: None declared.

\section{References}

1 World Health Organization. WHO report on the global tobacco epidemic 2015: raising taxes on tobacco. http://apps.who.int/iris/bitstream/10665/178577/1/WHO_NMH_PND_15.5_eng.pdf?ua=1\&ua=1. Date last accessed: October 20, 2016.

2 Frazer K, Callinan JE, McHugh J, et al. Legislative smoking bans for reducing harms from secondhand smoke exposure, smoking prevalence and tobacco consumption. Cochrane Database Syst Rev 2016. 